\title{
STUDY ON THE EFFECTS OF IRRIGATION INTERVALS AND DROUGHT STRESS ON YIELD AND YIELD COMPONENTS OF FOUR MAIZE CULTIVARS IN IRAN
}

\author{
FARroKhI, G. ${ }^{1}-$ MOAVENI, P. ${ }^{1 *}$-MOZAFARI, H. ${ }^{1}-$ MAJIDI-HERAVAN, E. ${ }^{2}-$ SANI, B. ${ }^{1}$ \\ ${ }^{1}$ Department of Agronomy, Shahr-e-Qods Branch, Islamic Azad University \\ 37541-13115 Tehran, Iran \\ (e-mails:farrokhi_ghr@yahoo.com; mozafarihamid@yahoo.com,Dr.b.sani@gmail.com) \\ ${ }^{2}$ Department of Agronomy, Science and Research Branch, Islamic Azad University \\ 14778-93855 Tehran, Iran \\ (e-mail:majidi_e@yahoo.com) \\ *Corresponding author \\ e-mail: payam.moaveni@yahoo.com \\ (Received $24^{\text {th }}$ Jan 2018; accepted $2^{\text {nd }}$ May 2018)
}

\begin{abstract}
This study was conducted in order to examine the effects of irrigation intervals and drought stress on crop yield and its components for four maize cultivars. The split-plot in the (RCBD) design was employed to conduct this study with three replications over a period of two years. After the establishment of all plants the irrigation was controlled in the following intervals at seven treatments: 7 days, 10 days, 12 days, 14 days until the end of the growing period and from the 3-leaf to 7-leaf stages withholding the irrigation. After that, irrigation was performed every 10 days, 12 days and 14 days respectively as the main factor. The cultivars included KSC 704, 703, 705, and KSC706 as a sub-factor. As expected, there were significant differences between the cultivars: KSC705 and KSC704 showed the highest mean yield (199.9 g/plant) and the lowest mean yield (184.4 g/plant), respectively. Under conditions of severe stress, the best cultivar was KSC705 with a yield of 189.9 g/plant. In addition, under normal conditions, KSC705 turned out to be the best cultivar with a yield of $594.3 \mathrm{~g} / \mathrm{plant}$ with a 10-day irrigation interval. Therefore, this cultivar has been introduced as the most stable cultivar under the conditions of drought stress.
\end{abstract}

Keywords: corn, cultivars, drought stress, irrigation interval, yield

\section{Introduction}

Maize (Zea maize L.) is one of the most important cereal crops, grown principally during the summer season, in Iran and other Middle East countries. Corn is the staple food for many human populations in the world. It is a tropical plant, but, at present, it is intensively cultivated worldwide in subtropical and temperate regions. It can be successfully cultivated twice in a year. In developing countries, maize is a major source of income for many farmers, and is widely used in the food industry (Tagne et al., 2008).

Drought is one of the main environmental constraints that affects crop growth and production (Ashraf and Harris, 2004; Farooq et al., 2009). It has been estimated that up to $45 \%$ of the world's agricultural lands are subjected to drought (Bot et al., 2000). Moisture stress in crops depends on the different developmental stages and it could significantly affect the yield and other physiological traits (Chaves et al., 2009). An adequate supply of water for irrigation is one of the main factors that directly affects the growth and productivity of corn plants. Frequent water deficit is the primary limiting factor for crop production under arid and semi-arid conditions (Hussain et al., 2004). It 
affects nearly all the growth processes of the plant. The stress response depends upon the intensity, rate and duration of exposure, and the stage of crop growth (Wajid et al., 2004). Sun et al. (2006), stated that the critical plants were more sensitive to water stress, which is reflected in the significant reduction in most of the growth parameters. Ibrahim et al. (2007) reported that the highest values of plant height, ear characteristics (length, diameter, and weight) as well as the ear and kernel yields of the corn plants per feddan (f.e: 1 feddan $=0.42$ ha) in both seasons were obtained under the irrigation interval of 10 days, followed by 14, and 18 days. Aydinsakir et al. (2013) showed that different irrigation levels, when applied (full irrigation with no water stress and slight, mild, severe water stress, and no irrigation), have statistically significant effects on the yield components, such as the anthesis-silking interval, plant height, ear diameter, ear length, kernel number, and 100 kernels weight, except for the ear number. In addition, it was found that the cultivars had significantly different responses to water deficit. In another research, Jafari et al. (2012), showed that BC504 and BC652 produced the highest yields, and BC678 and NS504 produced the lowest yields under optimal, and stress conditions, respectively.

The aim of this study was to evaluate the effects of irrigation intervals at the critical stages of phonological, morphological, and physiological growth on yield and yield components of the four maize cultivars.

\section{Materials and methods}

Research studies were performed in 2015 and 2016 in a field experiment. The splitplot in the Randomized Complete Block Design (RCBD) was employed to conduct this study with three replications during a period of 2 years in the Islamic Azad University of Arak in the Markazi Province in Iran. Arak is the capital of Markazi province in Iran located with the latitude of 34.09 and the longitude of 49.69 at a mean elevation of 1748 $\mathrm{m}$ above sea level. Based on coupon divisions, this area is considered to be a desert temperate zone. The annual temperature difference is high. The average temperature and precipitation in this region are $18{ }^{\circ} \mathrm{C}$ and $255 \mathrm{~mm}$ respectively; July with an average temperature of $37^{\circ} \mathrm{C}$ the warmest month and February with an average of $-5{ }^{\circ} \mathrm{C}$ the coldest month. Weather data were collected from the weather station was located $1 \mathrm{~km}$ from the trial location. Average weather conditions at Arak area during the study are shown in Table 1. The soil at the trial site with its main characteristics presented in Table 2.

The irrigation intervals were as follows: I1: 7 days (control); I2: 10 days; I3: 12 days; I4: 14 days; and from the 3-leaf to 7-leaf stages the irrigation was withheld. After that, irrigation treated as the main factor was performed every I5: 10 days; I6: 12 days; I7: 14 days which was treated as the main factor. The cultivars included KSC 704(B73×MO17), KSC $703(\mathrm{~K} 47 / 3 \times \mathrm{MO} 17), \mathrm{KSC} 705(\mathrm{~K} 3640 / 3 \times \mathrm{MO} 17)$, and KSC $706(\mathrm{~K} 3547 / 4 \times \mathrm{MO} 17)$ as sub-factors.

The land preparation was carried out by plowing, discing, land leveling, and furrowing before planting the seeds. The seeds were planted manually, and each plot contained 5 rows with a length of $4 \mathrm{~m}$, and a distance of $0.5 \mathrm{~m}$ was maintained between each row. All plots were uniformly irrigated every 7 days for a month until the establishment of the seedlings (3-leaf stage). After matured physiological, selecting ten plants randomly from each subplot, some of the properties were studied, such as plant height, ear length, length of the non-inseminated ear, ear diameter, cob diameter, cob 
weight, number of ears per plant, number of kernels per plant, kernel yield, number of kernel rows per ear, number of kernels per row, 100 kernels weight, biological yield and harvest index.

Table 1. Values of daily average air temperature $\left(\mathrm{Ta},{ }^{\circ} \mathrm{C}\right)$, rainfall $(R, \mathrm{~mm})$, relative humidity $(\mathrm{RH}, \%)$

\begin{tabular}{c|c|c|c|c}
\hline Year & Month & Ta & R & RH \% \\
\hline \multirow{4}{*}{2015} & June & 26.72 & 0 & 15.57 \\
& July & 27.87 & 60 & 17.61 \\
& August & 26.65 & 0 & 17.9 \\
& September & 21.62 & 42 & 30.93 \\
& October & 13.29 & 42 & 40.08 \\
& Average/Total & 23.23 & 144 & 24.42 \\
\hline \multirow{4}{*}{016} & June & 26.41 & 0 & 22.66 \\
& July & 28.43 & 19.35 & 21.16 \\
& August & 25.94 & 0 & 17.12 \\
& September & 22.73 & 0 & 22.16 \\
& October & 16.04 & 37 & 29.56 \\
& Average/Total & 23.91 & 56.35 & 22.53 \\
\hline
\end{tabular}

Table 2. Some physicochemical properties of the soil at 0 to $30 \mathrm{~cm}$

\begin{tabular}{c|c|c|c}
\hline $\mathbf{E c}(\mathbf{d S} / \mathbf{m})$ & 2.9 & $\mathbf{K}(\mathbf{a v a}).(\mathbf{p p m})$ & 435.2 \\
$\mathbf{p H}$ & 7.6 & $\mathbf{F e}(\mathbf{p p m})$ & 3.4 \\
$\mathbf{O C} \%$ & 2.34 & $\mathbf{Z n}(\mathbf{p p m})$ & 0.6 \\
TNV\% & 11.75 & Clay \% & 22.2 \\
$\mathbf{N \%}$ & 0.24 & Silt \% & 29.6 \\
P(ava.) (ppm) & 10.3 & Sand\% & 48.2 \\
\hline
\end{tabular}

The kernel yield was reported at moisture content of $14 \%$ and calculated in plant/g. To determine kernel yield, biological yield and harvest index, produced within two central rows in the field. Biological yield was recorded by weighing all the plants harvested from each plot and then converted into (plant/g). Then kernel yield and biological yield recorded on a dry weight basis. The harvest index was determined as follows:

$$
\mathrm{HI}=(\text { Economical yield } / \text { Biological yield }) \times 100
$$

Data regarding 100 kernels weight was recorded by counting actual number of 100 kernels at random and then were weighed with electronic balance.

The analysis of the variance (ANOVA) and the comparison of the mean values were performed by the SAS statistical software, and the Duncan test both at $5 \%$ level. 


\section{Results}

The results of the ANOVA indicated that the simple effects of the treatments (irrigation interval, and cultivars) were statistically significant for all the studied traits at $\mathrm{p}<0.01$. In addition, all traits were subjected to treatments $(\mathrm{p}<0.01)$ (Table 3). The data showed that withholding irrigation between the 3-leaf and 7-leaf stages resulted in height loss of the plant. According to the comparison of the mean values, the I1 and I7 treatments showed the highest $(168.6 \mathrm{~cm})$, and the lowest $(93.43 \mathrm{~cm})$ mean values of plant height, respectively. The height of the plants subjected to both irrigation intervals and withholding of water was dramatically lower than that of the plants under controlled irrigation. In addition, the irrigation intervals I5 and I6 showed 33\% and $44 \%$ reduction in plant height, respectively, in comparison with those under controlled irrigation. The cultivars showed no significant effects on plant height, in relation to the treatments interaction, for controlled irrigation; KSC704 showed the highest plant height, however for the irrigation interval of 14 days and withholding irrigation, the highest mean height was obtained for KSC705 (Fig. 1).

Table 3. Analysis of variance for studied traits

\begin{tabular}{c|c|c|c|c|c|c|c|c|c}
\hline S. o V. & Df & Plant height & $\begin{array}{c}\text { Ear } \\
\text { length }\end{array}$ & $\begin{array}{c}\text { Non- } \\
\text { inseminated } \\
\text { ear length }\end{array}$ & $\begin{array}{c}\text { Ear } \\
\text { diameter }\end{array}$ & $\begin{array}{c}\text { Cob } \\
\text { diameter }\end{array}$ & $\begin{array}{c}\text { Cob } \\
\text { weight }\end{array}$ & $\begin{array}{c}\text { Ear } \\
\text { number } \\
\text { per } \\
\text { plant }\end{array}$ & $\begin{array}{c}\text { Number of } \\
\text { kernels } \\
\text { per plant }\end{array}$ \\
\hline Year & 1 & $49050.01 * *$ & $374.021 * *$ & $3.262^{* *}$ & $36.774 * *$ & $23.118^{* *}$ & 81.343 & $76.006 * *$ & 34312.29 \\
R(Y) & 4 & 450.117 & 18.639 & 0.337 & 0.773 & 1.267 & $288.86^{* *}$ & 0.685 & 168780.6 \\
FactorA & 6 & $15043.49 * *$ & $11.489 * *$ & $1.692^{* *}$ & $2.15^{* *}$ & $3.036^{* *}$ & $149.88^{* *}$ & $3.409 * *$ & $428568.2 *$ \\
YA & 6 & $2030.964 * *$ & 23.914 & $2.866^{* *}$ & 1.312 & 1.039 & $184.051^{* *}$ & $7.742 * *$ & $1651658^{* *}$ \\
Error & 24 & 470.72 & 10.984 & 0.38 & 0.628 & 0.705 & 41.267 & 0.837 & 173317.8 \\
FactorB & 3 & 96.743 & $15.575^{* *}$ & $0.707 *$ & $0.438^{*}$ & $0.87 * *$ & $21.61 *$ & 1.149 & $218175^{*}$ \\
YB & 3 & 317.763 & 8.708 & $0.569 *$ & 0.241 & $0.508^{*}$ & $61.335^{* *}$ & 0.244 & 112731.4 \\
AB & 18 & $478.494 * *$ & $11.91 * *$ & $0.906^{* *}$ & $0.396 * *$ & 0.218 & $20.8 * *$ & $1.033 *$ & $336976.7 * *$ \\
YAB & 18 & $443.44 * *$ & $11.676^{* *}$ & $1.085^{* *}$ & $0.253^{*}$ & $0.225^{*}$ & $14.057 *$ & 0.869 & $279362.9 * *$ \\
Error & 84 & 176.431 & 3.968 & 0.207 & 0.129 & 0.133 & 8.363 & 0.569 & 78965.71 \\
Cv\% & & 11.45 & 12.53 & 30 & 8.89 & 12.66 & 24.1 & 23.7 & 29.3 \\
\hline
\end{tabular}

\begin{tabular}{c|c|c|c|c|c|c|c|c}
\hline S. o V. & Df & Kernel yield & $\begin{array}{c}\text { Row } \\
\text { number } \\
\text { per ear }\end{array}$ & $\begin{array}{c}\text { Kernel } \\
\text { numberper } \\
\text { row }\end{array}$ & $\begin{array}{c}\mathbf{1 0 0} \\
\text { kernels } \\
\text { weight }\end{array}$ & $\begin{array}{c}\text { Kernel number } \\
\text { per ear }\end{array}$ & $\begin{array}{c}\text { Biological } \\
\text { yield }\end{array}$ & $\begin{array}{c}\text { Harvest } \\
\text { Index }\end{array}$ \\
\hline Year & 1 & 89980.82 & $193.887 * *$ & $3347.054 * *$ & 76.937 & $1108393 * *$ & $1156633 * *$ & $195837.3 * *$ \\
R(Y) & 4 & 70990.24 & 2.383 & 76.441 & 146.852 & 9590.113 & 1958.957 & 34.224 \\
FactorA & 6 & $94868.23 *$ & $14.208^{* *}$ & $152.993 * *$ & $202.706 *$ & $65516.72 * *$ & $7213.282 * *$ & 97.215 \\
YA & 6 & $121417.9 *$ & $11.987 * *$ & $147.108^{*}$ & $230.798 *$ & $50695.74 *$ & $19024.58 * *$ & 67.4 \\
Error & 24 & 37775.28 & 2.396 & 51.851 & 79.159 & 14188.06 & 1756.094 & 72.816 \\
FactorB & 3 & 22430.87 & 2.094 & 41.086 & 55.826 & 5720.941 & 1684.432 & 161.348 \\
YB & 3 & 33326.71 & $2.935^{*}$ & 37.814 & 11.46 & 7168.151 & $10987.62 * *$ & 106.921 \\
AB & 18 & $145399.87 * *$ & $5.015 * *$ & $34.675 *$ & $117.624 *$ & $13465.2 * *$ & $13410.96 * *$ & 72.761 \\
YAB & 18 & $81535.13 *$ & $1.928 * *$ & $41.853 * *$ & $178.599 *$ & $10299.35 * *$ & $10812.17 * *$ & 75.356 \\
Error & 84 & 29567.02 & 0.867 & 16.282 & 65.441 & 3924.427 & 907.529 & 68.523 \\
Cv\% & & 24.1 & 7.1 & 16.8 & 25.5 & 19.4 & 15.6 & 22.7 \\
\hline
\end{tabular}

*, ** significant at the 0.05 and 0.01 probability levels, respectively 


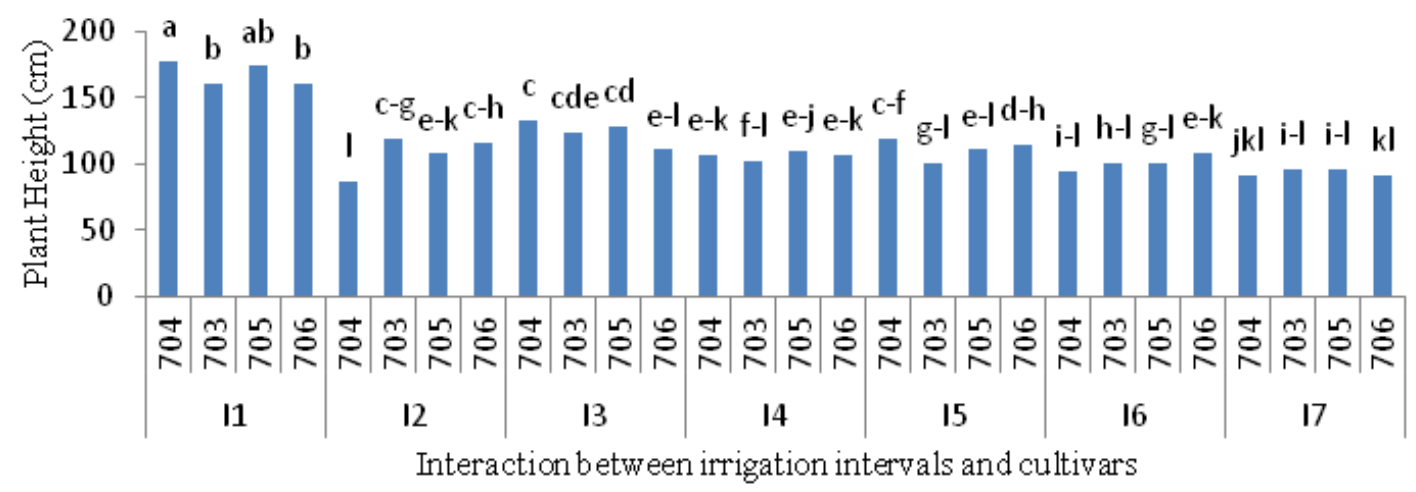

Figure 1. Comparison of mean values of interaction treatments on plant height. Mean values in each column marked by similar letters are not significantly different at the $5 \%$ probability level

(Duncan 5\%)

A reduction of 5.8\% in the ear length was observed in the case of I7 in comparison with I1 (controlled irrigation) (Fig. 2). The effects of interaction between irrigation and cultivars showed that the highest mean height $(18.33 \mathrm{~cm})$ and lowest mean height $(12.86 \mathrm{~cm})$ were obtained by I4V4, and I3V4, respectively. The non-inseminated ear length measured under controlled conditions was significantly lower than what was observed for the other irrigation intervals. The I6 treatment led to an increase of $9.6 \%$ in the non-inseminated ear length. In addition, KSC704 showed the lowest mean height $(1.31 \mathrm{~cm})$ among the cultivars. KSC706 demonstrated the lowest non-inseminated ear length for the 14 days irrigation interval along with withholding the irrigation effects between the 3-leaf and 7-leaf stages (Fig. 3).

Drought stress led to the reduction in the ear and cob diameter as compared to controlled irrigation. As drought stress increased, the ear and cob diameter significantly decreased. Among the cultivars, KSC705 showed the highest mean ear diameter $(4.15 \mathrm{~cm})$, and KSC706 showed the highest mean cob diameter $(3.07 \mathrm{~cm})$; however, the other cultivars showed no significant differences (Figs. 4 and 5). In the case of the I3 irrigation treatment, KSC703 showed the highest mean ear diameter, whereas KSC705 demonstrated the highest mean cob diameter. At the highest level of drought stress (I7), the highest ear diameter $(4.39 \mathrm{~cm})$, and cob diameter $(3.07 \mathrm{~cm})$ were obtained in KSC706.

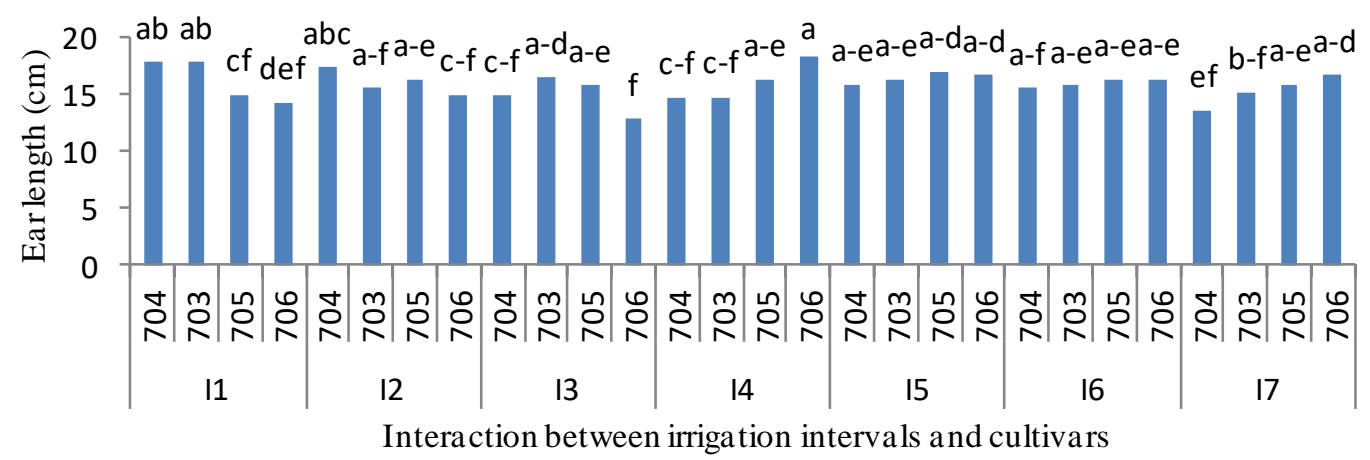

Figure 2. Comparison of mean values of interaction treatments on ear length. Mean values in each column marked by similar letters are not significantly different at the 5\% probability level

(Duncan 5\%) 


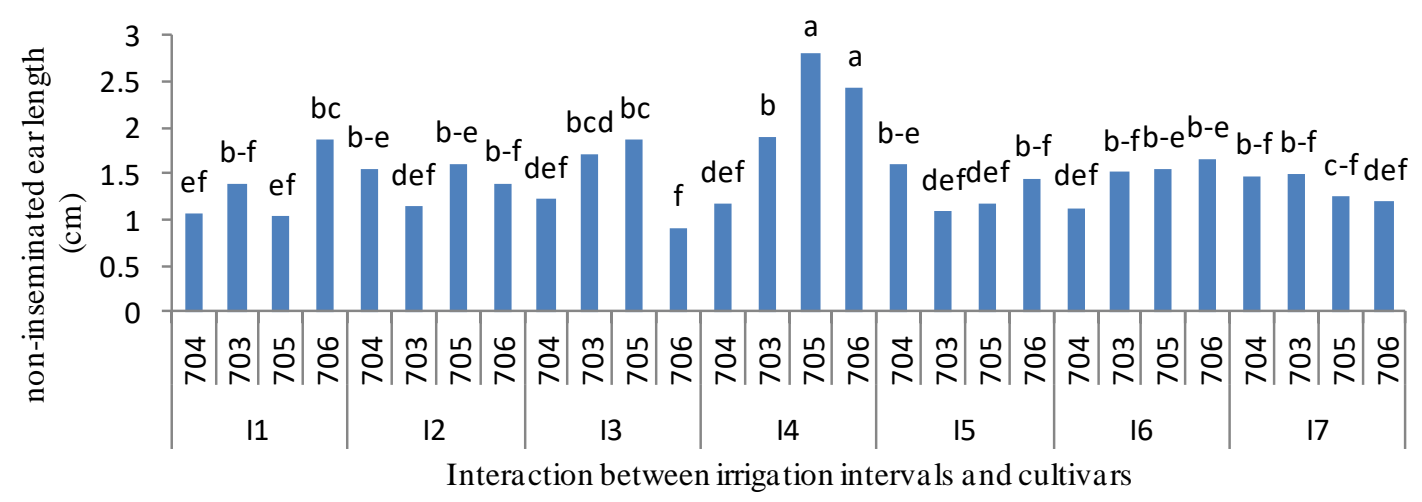

Figure 3. Comparison of mean values of interaction treatments on non-inseminated ear length. Mean values in each column marked by similar letters are not significantly different at the 5\% probability level (Duncan 5\%)

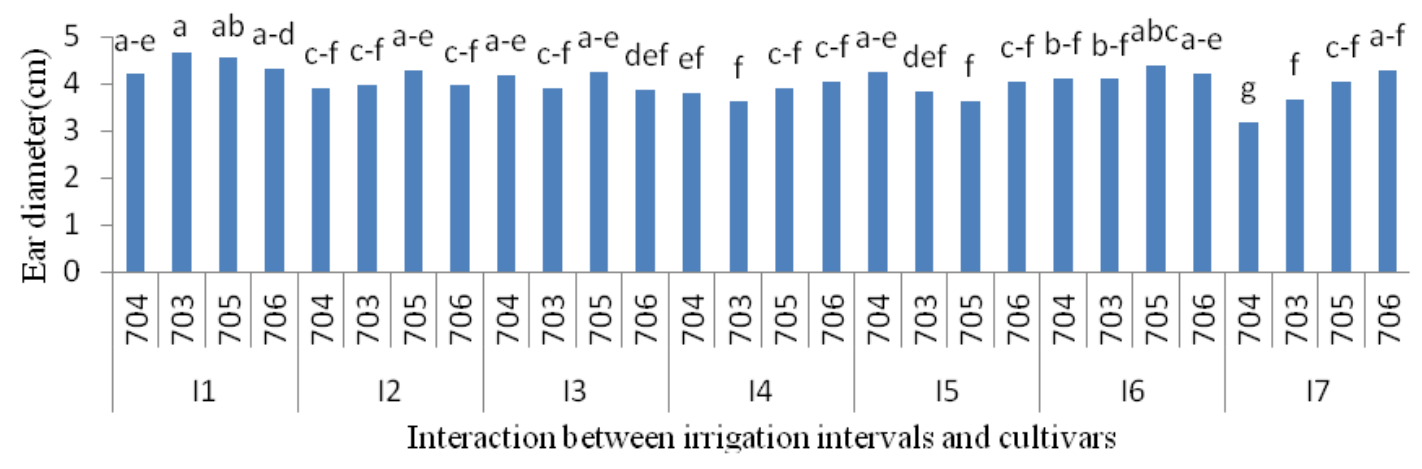

Figure 4. Comparison of mean values of interaction treatments on ear diameter. Mean values in each column marked by similar letters are not significantly different at the 5\% probability level (Duncan 5\%)

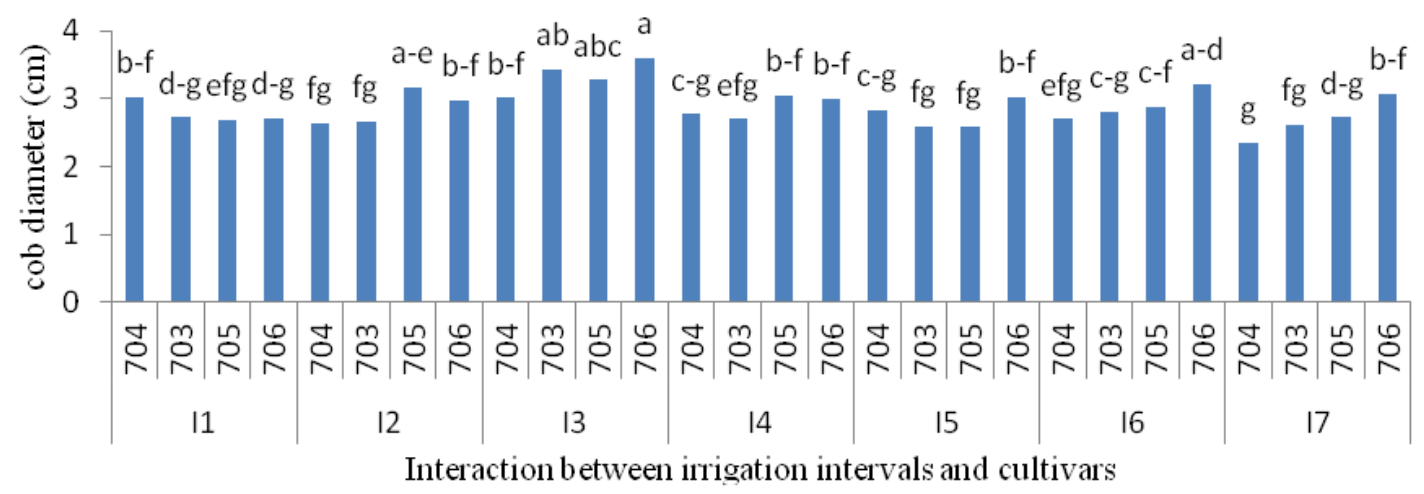

Figure 5. Comparison of mean values of interaction treatments on cob diameter. Mean values in each column marked by similar letters are not significantly different at the 5\% probability level (Duncan 5\%)

The number of kernels decreased steadily from 1:176 per plant at I1 to 825 per plant in the I7 treatment. Among the cultivars, KSC705 yielded the highest mean value for the number of kernels per plant (1047.17). KSC704 yielded the highest number of 
kernels per plant as compared to the other cultivars for the 14 days interval while withholding irrigation (Figs. 6, 7, 8, 9, 10, and 11).

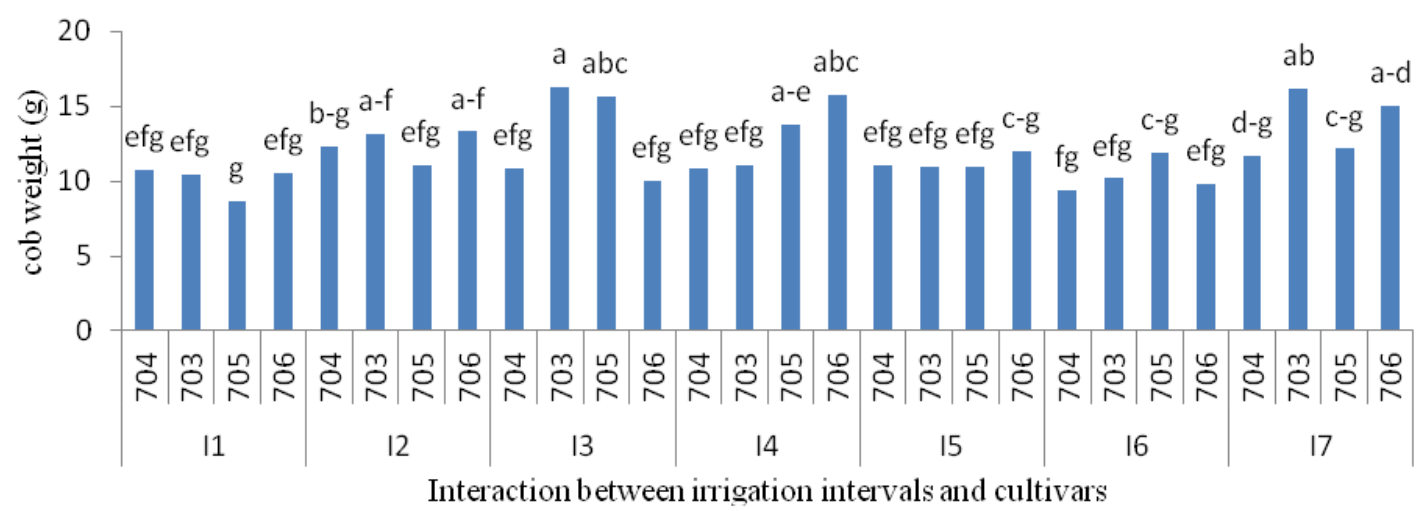

Figure 6. Comparison of mean values of interaction treatments on cob weight. Mean values in each column marked by similar letters are not significantly different at the $5 \%$ probability level (Duncan 5\%)

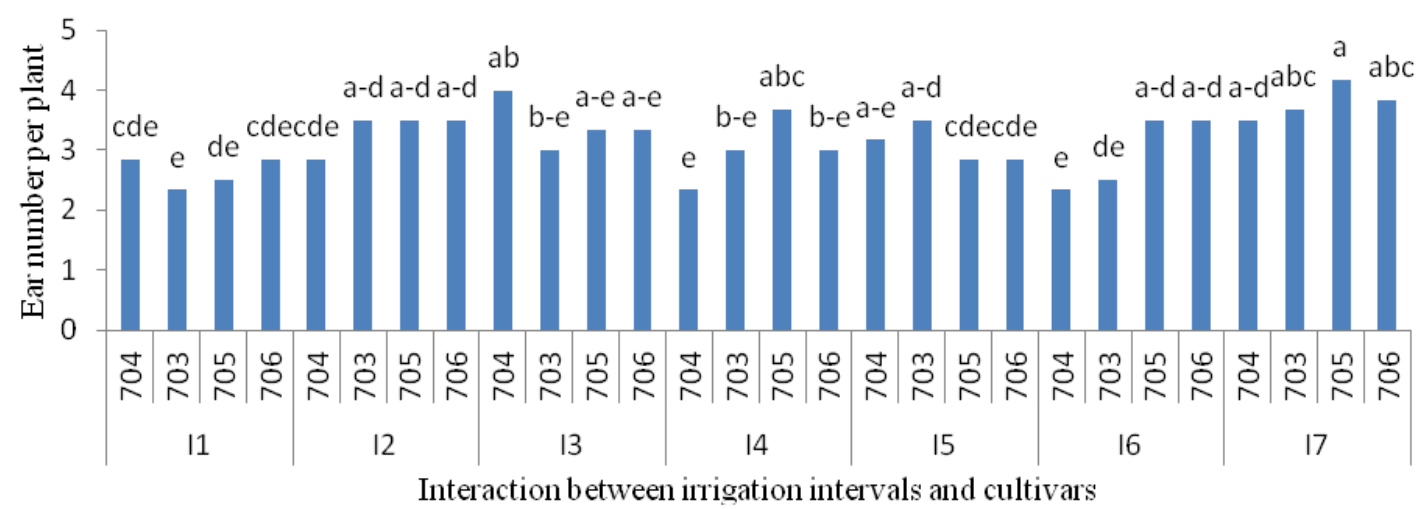

Figure 7. Comparison of mean values of interaction treatments on Ear number per plant. Mean values in each column marked by similar letters are not significantly different at the 5\% probability level (Duncan 5\%)

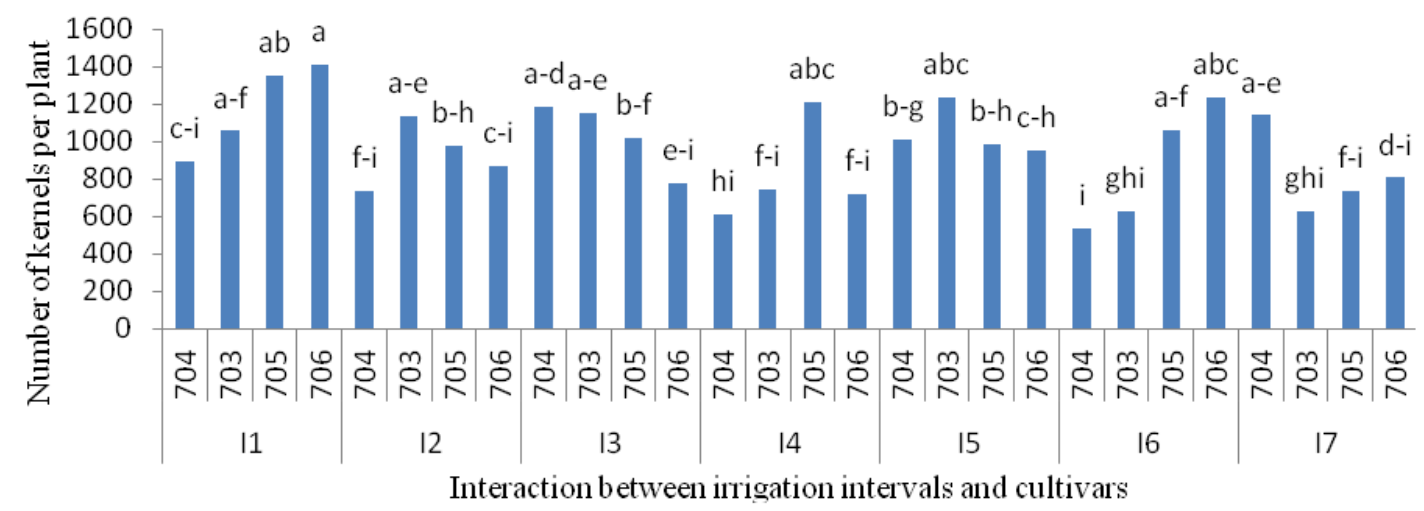

Figure 8. Comparison of mean values of interaction treatments on Number of kernels per plant Mean values in each column marked by similar letters are not significantly different at the 5\% probability level (Duncan 5\%) 


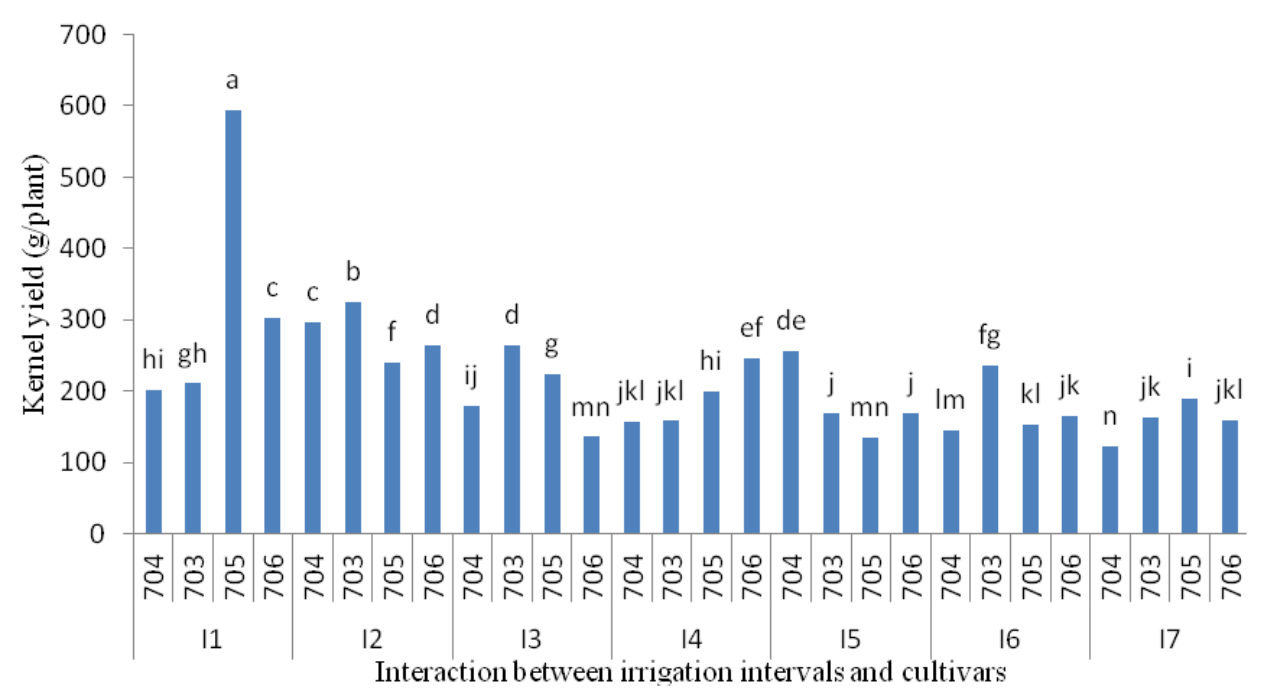

Figure 9. Comparison of mean values of interaction treatments on kernel yield. Mean values in each column marked by similar letters are not significantly different at the 5\% probability level

(Duncan 5\%)

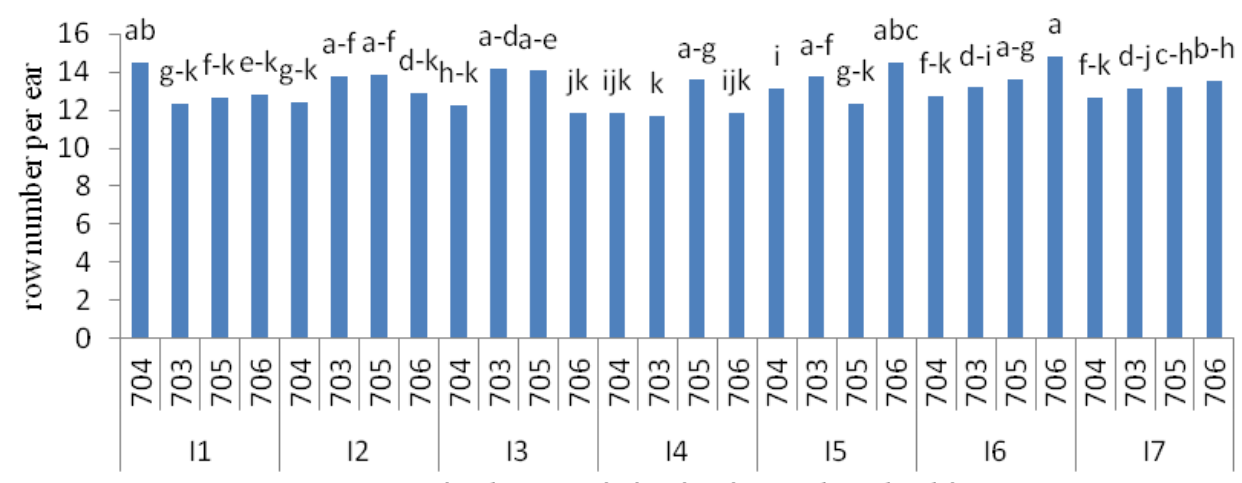

Interaction between irrigation intervals and cultivars

Figure 10. Comparison of mean values of interaction treatments on row number per ear. Mean values in each column marked by similar letters are not significantly different at the 5\% probability level (Duncan 5\%)

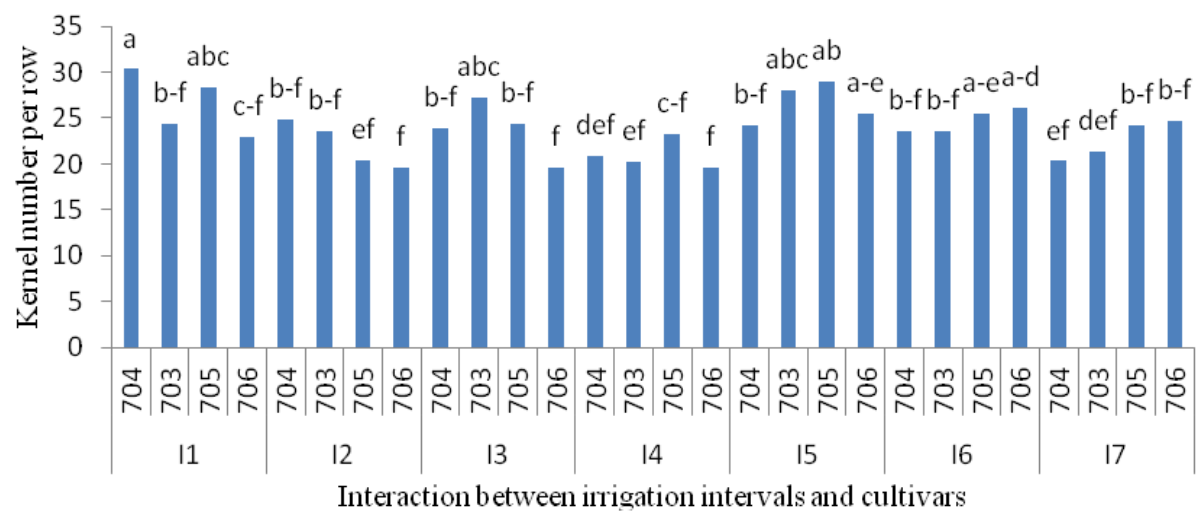

Figure 11. Comparison of mean values of interaction treatments on kernel number per row. Mean values in each column marked by similar letters are not significantly different at the 5\% probability level (Duncan 5\%) 
The weight of 100 kernels of the severely stressed plants was the least compared to mildly stressed and well-watered plants. The irrigation interval of 14 days along with withholding the irrigation led to a significant reduction of $25 \%$ in the kernel weight compared to the kernel weight from plants under the controlled irrigation. The highest $(24.27 \mathrm{~g})$, and lowest $(21.81 \mathrm{~g})$ mean kernel weights were obtained for KSC703 and KSC705; however, KSC706: and KSC705 showed no significant differences (Figs. 12 and 13).

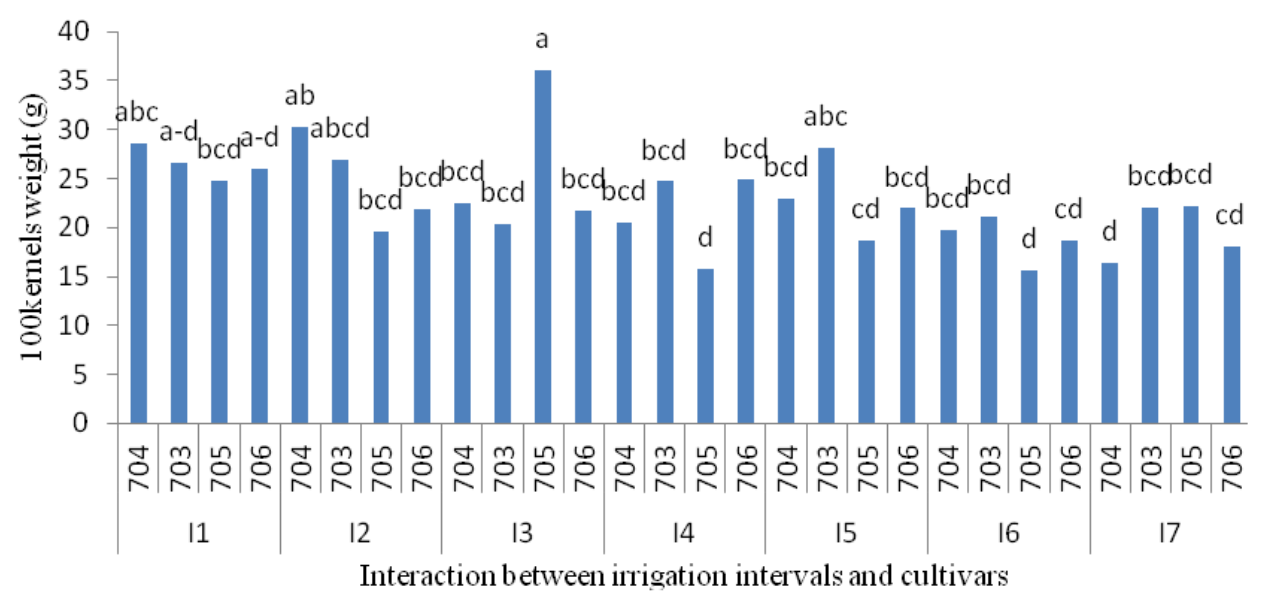

Figure 12. Comparison of mean values of interaction treatments on 100 kernels weight ( $g$ ). Mean values in each column marked by similar letters are not significantly different at the 5\% probability level (Duncan 5\%)

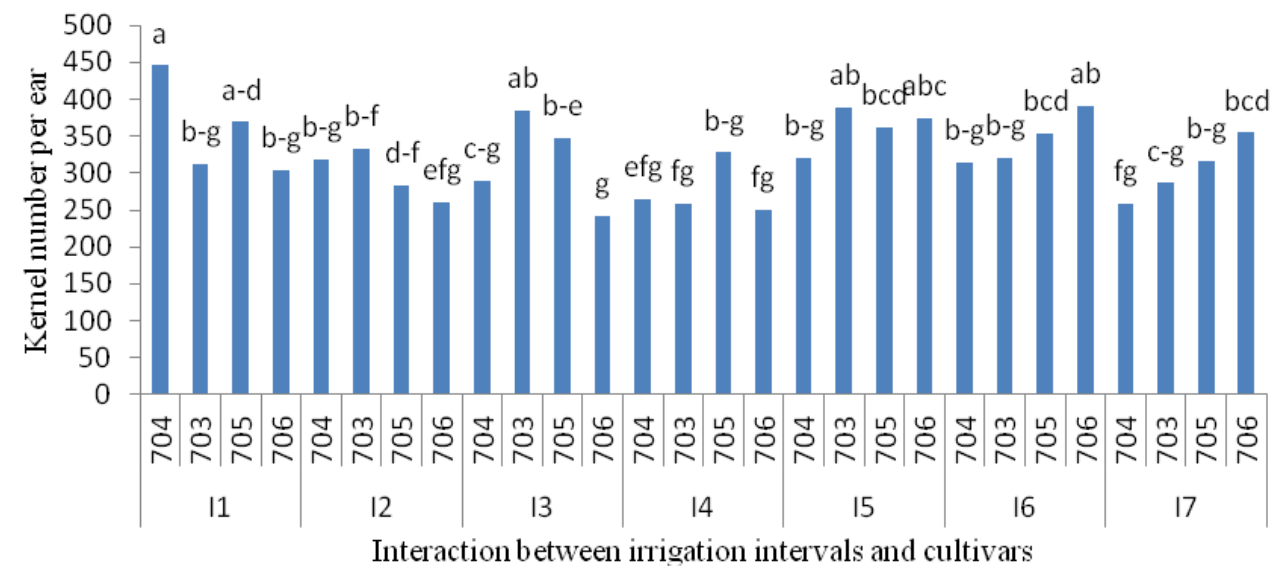

Figure 13. Comparison of mean values of interaction treatments on kernel number per ear. Mean values in each column marked by similar letters are not significantly different at the 5\% probability level (Duncan 5\%)

All the treatments showed a reduction in yield and yield components in comparison with controlled irrigation but the 10-day, 12-day irrigation intervals showed a similar effect on the yield. Among the irrigation intervals, the highest mean yield (327.47 g/plant) was obtained under controlled irrigation (I1), whereas the lowest mean yield (158.7 g/plant) was obtained in the I7 interval (Fig. 9). As expected, there were 
some significant differences among the cultivars; KSC705 showed the highest mean yield (248.8 g/plant), whereas KSC704 showed the lowest mean yield (194.6 g/plant). Regarding the different irrigation intervals, the cultivars had different responses, such that, under the I1 and I7 treatments, the highest yields obtained from KSC705 were $594.3 \mathrm{~g} /$ plant, and $189.5 \mathrm{~g} / \mathrm{plant}$, respectively.

The biological yield represents the total dry matter at the time of harvest (Figs. 14 and 15).

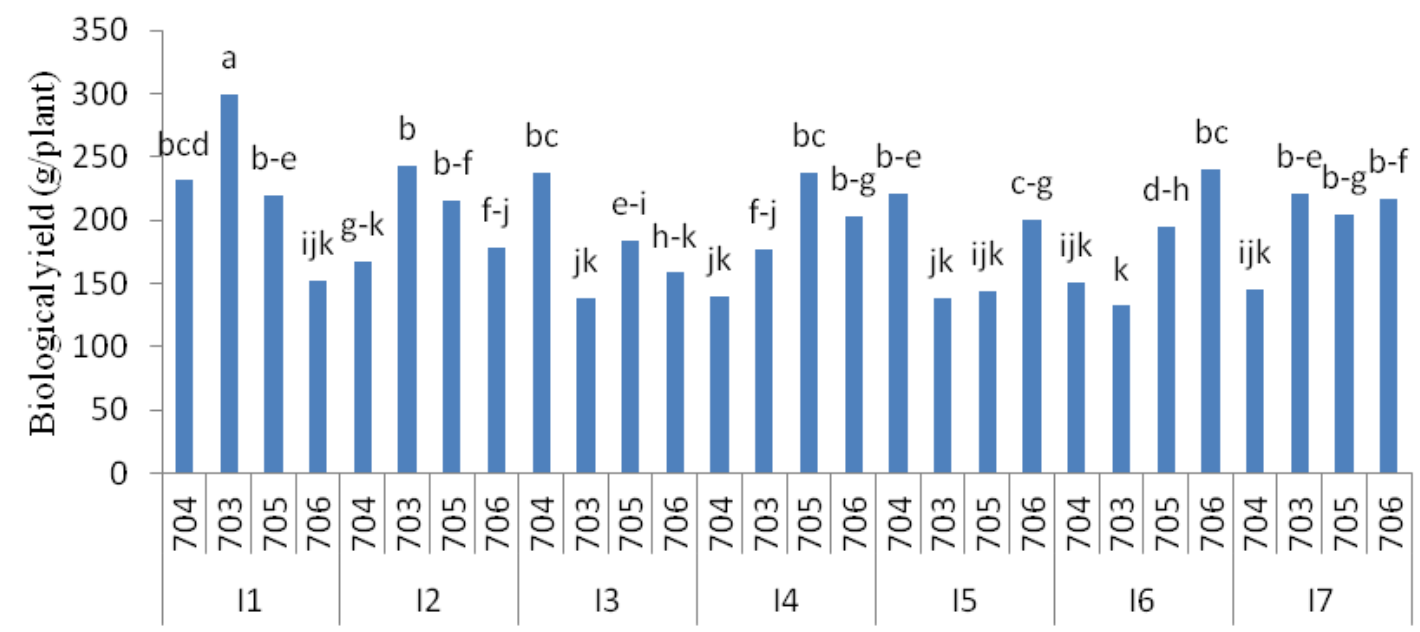

Interaction between irrigation intervals and cultivars

Figure 14. Comparison of mean values of interaction treatments on biological yield. Mean values in each column marked by similar letters are not significantly different at the 5\% probability level (Duncan 5\%)

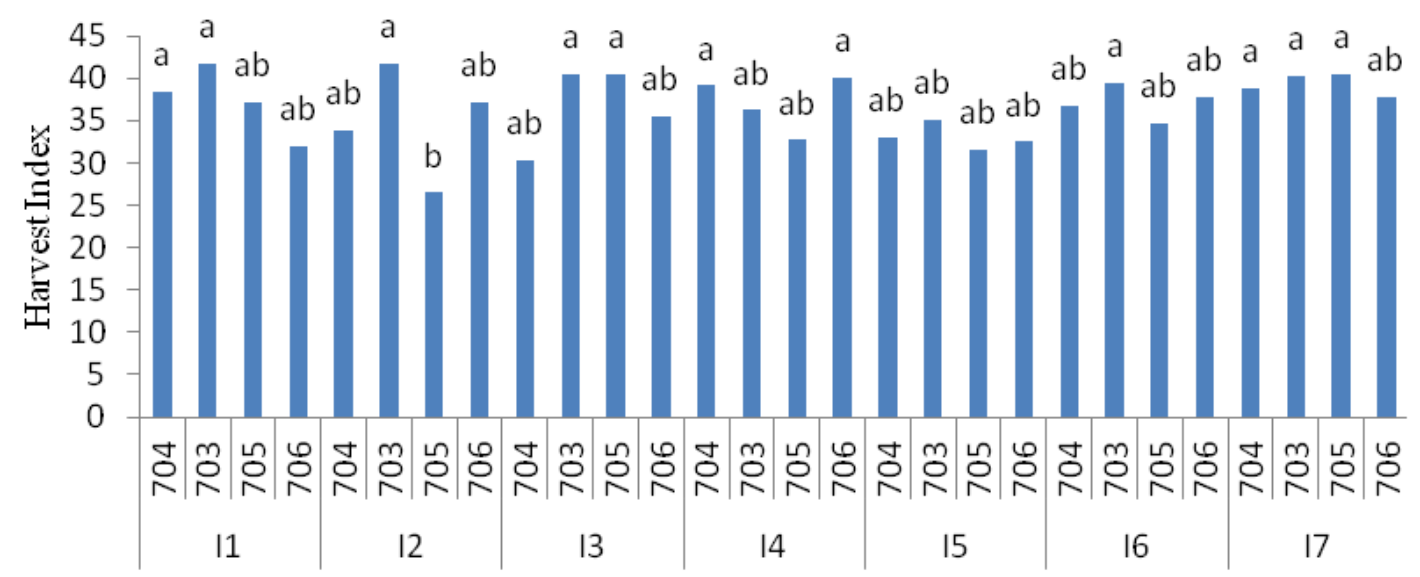

Interaction between irrigation intervals and cultivars

Figure 15. Comparison of mean values of interaction treatments on harvest index. Mean values in each column marked by similar letters are not significantly different at the 5\% probability level (Duncan 5\%)

The irrigation intervals I2, I3, I4, I5, I6, and I7 showed 10\%, 20\%, 16\%, 21\%, 20\%, and $12 \%$ reduction in yield, respectively, as compared to the yield in controlled irrigation. A longer stay in the green period under optimum irrigation led to an increase in the 
biological yield. It seems that for hybrids with a shorter growth, the biological yield is less, as KSC705 and KSC704 had the highest (199.9 g/plant) and lowest (184.4 g/plant) mean yields, respectively.

\section{Discussion}

Under drought stress, the rate of water intake by the plant is not high enough to maintain the turgidity of the leaves, and resultantly, the dry yield per unit of water consumed decreases (Kramer, 1949). The reduction in the growth and yield parameters under the irrigation interval of 14 days may also occur due to the imbalance of soilwater-air relation under these conditions, which leads to a reduction in the photosynthetic activity as well as inducing adverse relations between the hormones and biological processes in all organs of the plant (Ibrahim et al., 2005). Badr et al. (2003) and Thalooth et al. (2006) stated that plants grown under water-stress conditions show significant reduction in all the photosynthetic pigment content compared to unstressed plants. In accordance with our results, Ibrahim et al. (2007) mentioned that corn plants showed significant reduction in yield when the soil moisture content was decreased under an irrigation interval of 18 days. This effect could be attributed mainly to the excessive water stress in the root-zone causing an imbalance in the plant's nutrition. These results are in concurrence with those reported by many investigators, such as Larson (1975), Navari-Izzo et al. (1990), Osman et al. (1994), Kramer (1995), Ibrahim et al. (2005), and Thalooth et al. (2006); they noticed that under water depletion, the total nitrogen content, protein content as well as amino acids decreased in Zea mays and Helianthus annuus. They related this effect to the unbalanced soil-water-air relations that lead to the reduction in the photosynthetic activity as well as the induction of adverse relations between hormones and biological processes in all organs of the plants. In addition, Badr et al. (2003) stated that the uptake of nutrients is closely linked to the water-soil conditions. It is expected that a decline in the available moisture in the soil might decrease the diffusion rate of nutrients from the soil matrix to the roots.

\section{Conclusion}

This study was performed to evaluate the effects of irrigation intervals and drought stress on yield and yield components of four maize cultivars. Our results demonstrated that all treatments showed a reduction in yield when compared to control irrigation; however, the irrigation intervals of 10 days and 12 days showed a similar effect. Controlled irrigation (I1) demonstrated the highest mean yield of $327.4 \mathrm{~g} / \mathrm{plant}$, whereas the lowest mean yield was $158.6 \mathrm{~g} / \mathrm{plant}$ obtained under the $\mathrm{I} 7$ irrigation interval. As expected, there were significant differences between the cultivars; KSC705 and KSC704 showed the highest (199.9 g/plant) and lowest (184.4 g/plant) mean yields, respectively. Therefore, in comparing cultivar KSC704 with other cultivars under low irrigation conditions, KSC704 was affected by drought stress, while other cultivars showed less effect on irrigation conditions.

Irrigation methods contribute to increase the water use efficiency and decrease the amount of irrigation water each time and ultimately to increase the net profits. This experiment demonstrates the traits and indices have the highest correlation with yield and by these two factors identify sensitivity and tolerant cultivars are recognized. 
Irrigation intervals are effective on the performance and water use efficiency of different maize hybrids.

A professional management is required to get the best results from the cultivation of each product. Well-timed irrigation is an important factor meaning that the plant receives water at the right time and as it needs. With proper irrigation, the product is not affected by water stress, and water waste and energy losses are minimized. On the other hand, one of the basic steps in managing irrigation is right planning.

It is imperative to calculate the appropriate irrigation interval for other crops, which is suggested to be in different geographic latitudes.

\section{REFERENCES}

[1] Ashraf, M., Harris, PJ. (2004): Potential biochemical indicators of salinity tolerance in plants. - Plant Sci. 166: 3-16.

[2] Aydinsakir, K., Erdal, S., Buyuktas, D., Bastug, R., Toker, R. (2013): The influence of regular deficit irrigation applications on water use, yield, and quality components of two corn (Zea mays L.) genotypes. - Agricultural Water Management 128: 65-71.

[3] Badr, M. M., Bassal, S. A. A., Ibrahim, E. M. (2003): Effect of preceding winter crops, nitrogen and phosphorous fertilizer levels on growth and yield of maize (zea mays L.). J. Agric. Sci. Mansoura Univ. 28(9): 6591-6601.

[4] Bot, A. J., Nachtergaele, F. O., Young, A. (2000): Land Resource Potential and Constraints at Regional and Country Levels. - World Soil Resources Reports 90, Land and Water Development Division, FAO, Rome.

[5] Chaves, M. M., Flexas, J., Pinheiro, C. (2009): Photosynthesis under drought and salt stress: regulation mechanisms from whole plant to cell. - Annals of Botany 103(4): 551560.

[6] Farooq, M., Wahid, A., Kobayashi, N., Fujita, D., Basra, S. M. A. (2009): Plant drought stress: effects, mechanisms and management. - Agron. Sustain. Dev. 29: 185-212.

[7] Hussain, A., Ghaudhry, M. R., Wajad, A., Ahmed, A., Rafiq, M., Ibrahim, M., Goheer, A. R. (2004): Influence of water stress on growth, yield and radiation use efficiency of various wheat cultivars. - Intl. J. Agric. Biol. 6: 1074-1079.

[8] Ibrahim, A. M., El-Yazal, S. S., El-Sayim, R. G. (2005): Response of maize vegetative growth and yield to partial N-mineral replacement by biological nitrogen fixation under different soil moisture stress. - J. Agric. Sci. Mansoura Univ. 30(4): 2259-2273.

[9] Ibrahim, S. A., Kandil, H. (2007): Growth, yield and chemical constituents of corn (Zea Maize L.) as affected by nitrogen and phosphors fertilization under different irrigation intervals. - Journal of Applied Sciences Research 3(10): 1112-1120.

[10] Jafari, A., Paknejad, F., Jami, A. A. (2012): Evaluation of selection indices for drought tolerance of corn (Zea mays L.) hybrids. - International Journal of Plant Production 3(4): 33-38.

[11] Kramer, P. J. (1949): Plant and Soil Water Relationships. - McGraw-Hill, New York.

[12] Kramer, P. J. (1995): Water Relation of Plant and Soil. - Academic Press, New York.

[13] Larson, K. L. (1975): Drought Injury and Resistant of Crop Plants. - In: Gupta, U. S. (ed.) Physiological Aspects of Dry Land Farming. Oxford and RHS Pub. Co., New Delhi.

[14] Navari-Izzo, F., Quartacci, M. F., Izzo, R. (1990): Water stress induced changes in protein and free amino acids in field grown maize and sunflower. - Plant Physiol. Biochem. 28(4): 531-537.

[15] Osman, M. A., Afify, A. S., Habba, E. E., Mergawi, R. A. (1994): Physiological effect of water stress on alkaloids and major constituents of Panc Ratum Maritimum. - J. Agric. Sci. Mansoura Univ. 19(7): 2227-2236. 
[16] Sun, H. Y., Liu, C. M., Zhang, X. Y., Shen, Y. J., Zhang, Y. Q. (2006): Effects of irrigation on water balance, yield and WUE of winter wheat in the North China Plain. Agricultural Water Management 85(1): 211-218.

[17] Tagne, A., Feujio. T. P., Sonna, C. (2008): Essential oil and plant extracts as potential substitutes to synthetic fungicides in the control of fungi. - International Conference Diversifying Crop Protection, 12-15 October La Grande-Motte, France.

[18] Thalooth, A. T., Tawfik, M. M., Magda, H. A. (2006): A comparative study on the effect of foliar application of zinc, potassium and magnesium on growth, yield and some chemical constituents of mungbean plants grown under water stress conditions. - World Journal of Agricultural Sciences 2(1): 37-46.

[19] Wajid, A., Hussain, A., Ahmed, A., Rafiq, M., Goheer, A. R., Ibrahim, M. (2004): Effect of sowing date and plant density on growth, light interception and yield of wheat under semi arid condition. - Intl. J. Agric. Biol. 6: 1119-1125. 